\title{
Staphylococcus aureus STRAINS ISOLATED FROM BOVINE MASTITIS SENSITIVITY TO ANTIBIOTICS
}

\author{
Bouzidi Said $^{1}$, Ghazi Kheira ${ }^{1}$, Meliani Samia ${ }^{2 *}$, Boulbair Ismail ${ }^{1}$, Chaouch Rouba ${ }^{1}$ \\ ${ }^{1}$ The Veterinary Sciences Institut, University of Tiaret, 14000, Algeria; \\ ${ }^{2 *}$ Nature and life sciences faculty, University of Tiaret, 14000, Algeria;
}

*Corresponding Author Meliani Samia, e-mail: meianisamia@ @otmail.com;

Received July 2020; Accepted August 2020; Published September 2020;

DOI: $\underline{\text { https://doi.org/10.31407/ijees10.406 }}$

\begin{abstract}
The aims of this work was to study the sensitivity of Staphylococcus aureus strains isolated from bovine mastitis antibiotics. A total of 22 pure strains of S. aureus were collected from 58 quarter milk samples from 29 (69,04\%) dairy cows detected with subclinical mastitis by California mastitis test (CMT). The isolates were subjected to an antibiogram. The tests showed that one strain among the isolates tested is MRSA (Methicillin resistant Staphylococcus aureus). This MRSA exhibited cross-resistance to all betalactamines which extends to other families of antibiotics. SASM strains also showed strong resistance. vis-à-vis penicillin $(95,23 \%)$ and tetracycline's $(90,47 \%)$ Resistance was also recorded vis-à-vis; the combination amoxicillin + clavulanic acid (47,61\%), erythromycin $(19,04 \%)$, the combination trimethoprim + sulfamethoxazole $(4,76 \%)$ and bacitracin $(9.52 \%)$. neomycin, gentamicin, ciprofloxacin and clindamycin were active on MRSA's. The high prevalence of subclinical mastitis and multi-resistant S. aureus strains testifies to the need for an effective control strategy based essentially on the early detection of subclinical mastitis, the identification of the causative agent and the study of its sensitivity to common antibiotics.
\end{abstract}

Keywords: Mastitis, SARM, Antibiogram, SASM, S. aureus. 